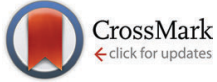

Cite this: Phys. Chem. Chem. Phys., $2015,17,27968$

Received 1st March 2015, Accepted 13th May 2015

DOI: $10.1039 / \mathrm{c} 5 \mathrm{cp} 01219 \mathrm{~h}$

www.rsc.org/pccp

\title{
Magnetic and noble metal nanocomposites for separation and optical detection of biological species
}

\author{
K. Bagga, ${ }^{\text {abcd D. F. Brougham, }{ }^{\text {ae }} \text { T. E. Keyes }}{ }^{\text {de }}$ and D. Brabazon $\star^{\text {abcd }}$
}

Nanoalloys and nanocomposites are widely studied classes of nanomaterials within the context of biological systems. They are of immense interest because of the possibility of tuning the optical, magnetic, electronic and chemical properties through particle composition and internal architecture. In principle these properties can therefore be optimized for application in biological detections such as of DNA sequences, bacteria, viruses, antibodies, antigens, and cancer cells. This article presents an overview of methods currently used for nanoalloy and nanocomposite synthesis and characterisation, focusing on $\mathrm{Au}-\mathrm{Ag}$ and $\mathrm{Fe}_{x} \mathrm{O}_{y}$ (aAu structures as primary components in detection platforms for plasmonic and magnetically enabled plasmonic bio-sensing.

\section{Introduction}

The field of nanocomposite materials is developing rapidly, with new material structures continuously being fabricated with the goal of producing synergistic performance improvements over those of the component phases. Structurally nanocomposite materials can be classified into three key types $^{1}$ (a) nanolayered composites composed of alternating layers of nanoscale dimension; (b) nanofilamentary composites composed of a matrix with embedded (and generally aligned) nanoscale diameter filaments; and (c) nanoparticulate composites composed of a matrix with embedded nanoscale particles.

Efforts have been made to improve the applicability and stability of composite systems, by combining different types of $\mathrm{NPs}$, e.g., luminescent, or magnetic and so on to introduce new physical, biological properties and multifunctional behaviour. Among the various morphologies of hybrid nanocomposite materials, nanoalloys represent an important class. The term nanoalloy is used to describe bi- or multi-metallic atom assemblies adopting atomic packing schemes with different chemical ordering patterns depending on the phase diagram and formation energies of its constituents. This includes atomically

\footnotetext{
${ }^{a}$ Advanced Processing Technology Research Centre, Dublin City University, Ireland. E-mail:Dermot.Brabazon@dcu.ie,Dermot.Brougham@dcu.ie

${ }^{b}$ Irish Separation Science Cluster, Dublin City University, Ireland

${ }^{c}$ School of Mechanical \& Manufacturing Engineering, Dublin City University, Ireland

${ }^{d}$ National Sensor Research Centre, Dublin City University, Ireland

${ }^{e}$ School of Chemical Sciences, Dublin City University, Ireland
}

randomly mixed, multi-domain, core-shell and onion-layered structures. ${ }^{2-4}$ The internal structures of nanoalloys are still not fully understood, despite advances in electron microscopy including energy-filtering. However, we shall see that, in many cases, control over optical properties can be obtained using different architectures, and secondly that there is as yet no clear consensus on the optimal structures.

Analysis of the literature shows that there has been a significant increase in the development of nanoalloys and nanocomposities across the fields of material science, physics, chemistry and biology. This upsurge in experimental ${ }^{5-7}$ and theoretical $^{8,9}$ work on nanoalloys is due to the unique enhanced physical optical and chemical binding properties arising from dimensional control at the nanoscale. ${ }^{10-13}$ For the bimetallic nanoalloys examined in this review, their properties do not depend only on one metal, but also on the composition and specific chemical ordering of the two metals. This provides significant additional experimental degrees of freedom, relative to the bulk alloy, as demonstrated in a large number of studies ${ }^{14-16}$ which highlight the role of the particle size, morphology, and their surface functionalisation in determining the emergent properties of interest. In this review we focus on noble-metal-based nanocomposites and hybrid systems of magnetic nanoparticles (iron oxide NPs) combined with organic and inorganic constituents (e.g., silica matrices, semiconductor and metal NPs). Representative examples of chemical, physical and biosynthetic routes to fabricate these nanoalloys and nanocomposites $\left(\mathrm{Au}-\mathrm{Ag} ; \mathrm{Fe}_{x} \mathrm{O}_{y} @ \mathrm{SiO}_{2} @ \mathrm{Au}\right.$; and $\left.\mathrm{Fe}_{x} \mathrm{O}_{y} @ \mathrm{Au}\right)$ are presented. A selection of papers exemplifying their development for application in separations and detection of biological targets are then discussed. 


\section{Surface plasmon resonance}

The interaction of light with a metal surface results in the collective oscillation of the surface free electrons. This phenomenon is called surface plasmon resonance (SPR) ${ }^{17}$ The noble metal components of nanoalloys have been widely used as efficient probes for localized surface plasmon resonance (LSPR), due to their strongly enhanced resonance at optical frequencies, making them excellent scatterers and absorbers in the visible spectral range. Their surface chemistry provides possibilities for functionalising with biomolecules, whilst retaining their bioactivity, which is particularly attractive for plasmonic sensing. The optical properties arise from different characteristics; higher scattering and extinction cross-sections, than the alternative semiconductor quantum dots or organic fluorophores. They have the advantages that they do not photobleach or blink, and that the surface plasmon resonance wavelength $\left(\lambda_{\text {spr }}\right)$ is highly sensitive to the local dielectric environment. The physical requirements for good plasmonic responses and in particular, narrow resonance bands in bimetallic systems include the formation of a monodisperse collection of particles with a plasmonic layer of even thickness or the formation of sub-domains of the same size.

\subsection{The promise of plasmonic nanocomposites for detection}

In the case of nanoalloys, $\mathrm{Au}-\mathrm{Ag}$ systems for instance, have been shown to exhibit tuneable LSPR in the visible range (400 to $520 \mathrm{~nm}$ ) of the spectrum ${ }^{18,19}$ (see Fig. $1^{24}$ ) resulting in plasmonic nanoparticles (NPs) which do not photobleach or blink and thus can serve as intense and robust labels for biosensors, immunoassays, cellular imaging and surface-enhanced spectroscopies. ${ }^{19}$ Although, Ag exhibits the sharpest and strongest bands among all metals, $\mathrm{Au}$ is preferred for biological applications due to its inert nature, biocompatibility, ${ }^{20}$ and the stable Au-thiol chemistry which can be exploited for immobilization of

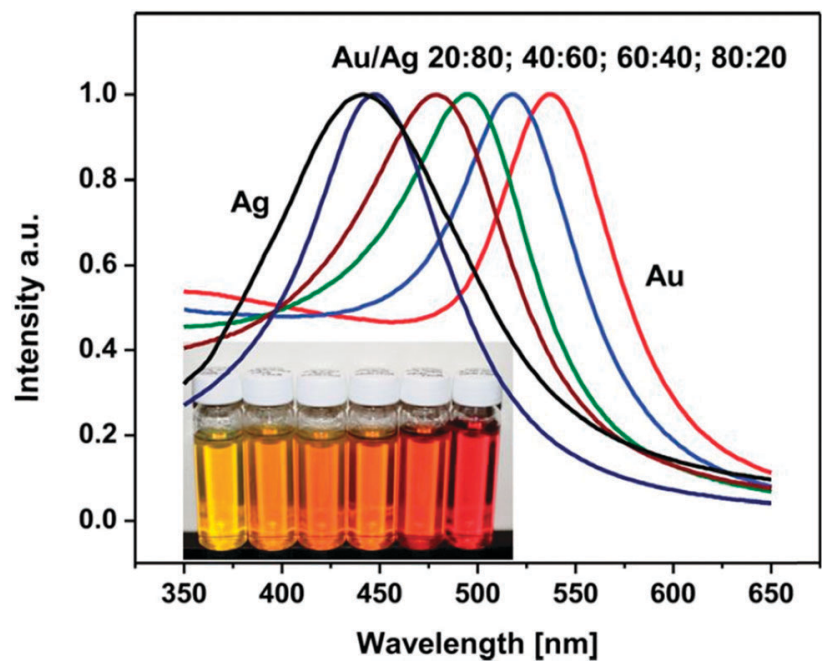

Fig. 1 Experimental spectra for different compositions of $60 \mathrm{~nm} \mathrm{Au} / \mathrm{Ag}$ alloy NPs. ${ }^{24}$ Reproduced from Ref. 24 with permission from The Royal Society of Chemistry. biomolecules. Thus Au-Ag nanoalloys offer a good compromise between plasmonic efficiency (from $\mathrm{Ag}$ ) and in vivo biocompatibility (from $\mathrm{Au}$ ) making them important for biological applications such as biosensors, ${ }^{21}$ immunoassay $^{22}$ and as imaging agents. ${ }^{23}$

\subsection{The promise of magnetic-plasmonic nanocomposites for detection}

Hybrid magnetic-plasmonic nanostructures contain both a magnetic and plasmonic phase offering a range of possibilities for detection..$^{25,26}$ These include optically monitoring the particles while controlling their motions magnetophoretically, through application of an external field gradient. To date most investigations have examined these particles for ex vivo imaging, with the added possibility of measuring internal forces within cells, ${ }^{27}$ or for tracking the transport of active agents within bio-reactors. ${ }^{28}$ Other investigators have examined simultaneous photoacoustic (plasmonic) and AC-field (magnetic) irradiation for thermal ablation of tissue which may prove advantageous for cancer treatment. ${ }^{26,29}$ Finally, the possibility of simultaneous magnetic resonance imaging in combination with the other functionalities, making use of the magnetic particles effect on the ${ }^{1} \mathrm{H}$ NMR relaxation times, has also been considered. ${ }^{30}$ Examples of magnetic nanoparticle cluster enhanced imaging include the imaging of macrophages and stem cell tracking. The addition of a plasmonic tag ${ }^{31}$ may make single magnetic particle tracking in individual cells tractable, the diffraction limit being overcome in dark field mode.

The magnetic component of the nanocomposite makes it possible to control the nanocomposites motion, against background Brownian motion or other flow dynamics, through the application of a static field gradient which penetrates tissue and is non-ionising. The physical requirements for useful magnetophoretic effects in an applied field gradient have been described. ${ }^{25}$ Essentially, the magnetic force is proportional to the magnetisable volume of the composite particles and to the difference in magnetic susceptibility compared to the background. Larger particles are therefore desirable; however above the superparamagnetic size limit aggregation is more prevalent, particularly in the presence of an external field, which drastically affects the plasmon resonance.

Various types of magnetic nanocomposites can be obtained by dispersing magnetic particles in a solid matrix ${ }^{32}$ in a liquid matrix ${ }^{33}$ or combined with another nanoscale component. ${ }^{34}$ Amongst those that have been reported are (a) $\mathrm{Fe}_{3} \mathrm{O}_{4}$ magnetic nanoparticle core plasmonic shell nanoparticles $\mathrm{Fe}_{3} \mathrm{O}_{4} @ \mathrm{Au}^{35-37}$ (b) $\mathrm{Fe}_{3} \mathrm{O}_{4} / \gamma-\mathrm{Fe}_{2} \mathrm{O}_{4}$ nanoparticles decorated with Au nanoparticles, including dumbbell arrangements; ${ }^{38,39}$ (c) $\mathrm{Fe}_{3} \mathrm{O}_{4} @ \mathrm{SiO}_{2} @ \mathrm{Au}$ nanoparticle cluster core plasmonic shell composites; ${ }^{40}$ and (d) plasmonic cores decorated with $\mathrm{FeO}$ nanoparticles, ${ }^{41}$ see for instance Fig. 2. For the purpose of this article much of the focus is on type (a); the $\mathrm{FeO} @ \mathrm{Au}$ configuration is the arrangement which is most clearly defined structurally, whose properties are best understood, and which is most commonly adopted. 


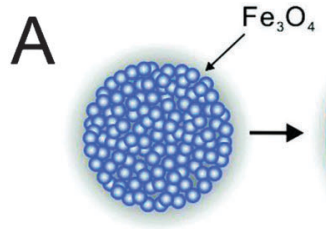

(i)

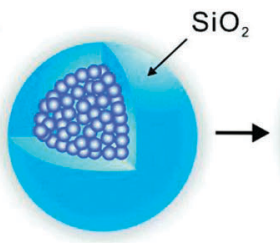

(ii)

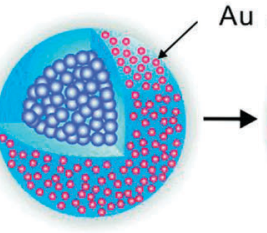

(iii)

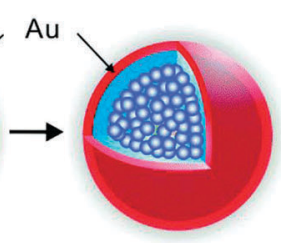

(iv)
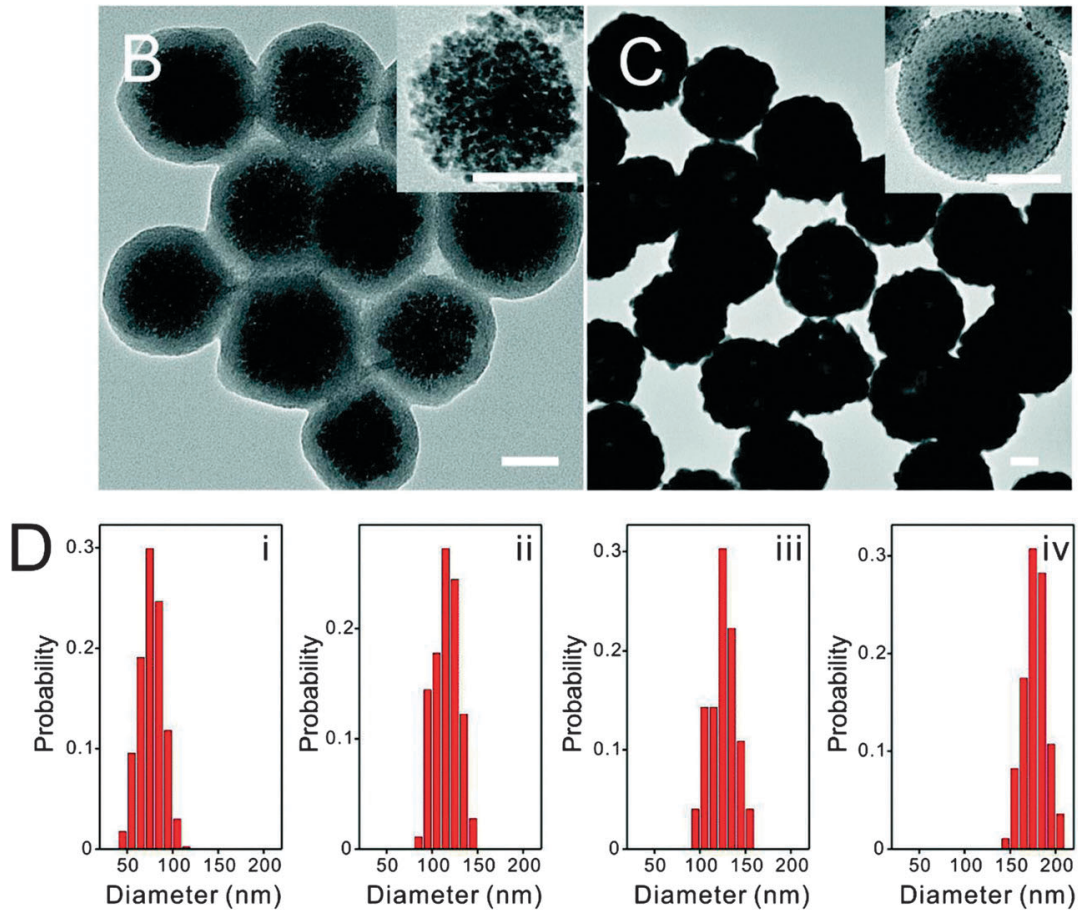

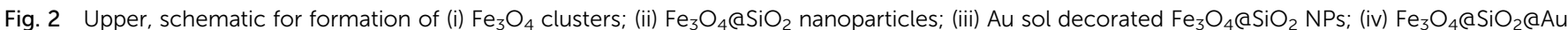
NPs. Middle TEM images of (ii) and (iv), all scale bars are $50 \mathrm{~nm}$. Lower TEM size distributions of (i) to (iv). ${ }^{40}$ Reproduced from Ref. 40 with permission from The Royal Society of Chemistry.

\section{Preparation methods of nanocomposites}

The methods of synthesis of nanocomposites can be broken into chemical, physical and bio-synthesis methods. These preparation methods are detailed below as applicable to $\mathrm{Au}-\mathrm{Ag}$ nanoalloys and FeO@Au nanocomposites.

\subsection{Preparation of $\mathrm{Au}-\mathrm{Ag}$ nanoalloy systems}

(a) Chemical synthesis. Methods for chemical synthesis of $\mathrm{Au}-\mathrm{Ag}$ nanoalloys and nanocomposites have evolved quickly over the past few years with a number of strategies developed to obtain controlled size and shape. Monodisperse Au-Ag colloids with defined size and shape are required to reproducibly achieve tuneable and sharp plasmon resonance bands for diagnostic applications. Reduction of $\mathrm{Au}$ and $\mathrm{Ag}$ salts mixed with sodium citrate in refluxing aqueous solution has been widely reported to yield $\mathrm{Au}-\mathrm{Ag}$ alloy nanoparticles with tunable SPR band by varying the molar fractions of gold. ${ }^{42} \mathrm{~A}$ seedmediated approach ${ }^{43}$ has also been reported to synthesize $\mathrm{Au}-\mathrm{Ag}$ core-shell nanorods from silver ions, using gold nanorods as seeds. Other methods for the synthesis of $\mathrm{Au}-\mathrm{Ag}$ nanoalloys include sputter deposition in ionic liquids, ${ }^{44}$ photochemical synthesis, ${ }^{45}$ and a unique two layer (TL) deposition of Au- and Ag-incorporated inorganic-organic hybrid silica sols. ${ }^{46}$

The synthesis of monodisperse Au-Ag nanoalloy particles in a one-pot approach was reported for the first time by Sun et $a l^{47}$ The composition of Au-Ag alloy was controlled through the ratio of the precursors and growth time during the synthesis. For example, with $2 \mathrm{mmol}$ of $\mathrm{AgNO}_{3}, 0.2 \mathrm{mmol}$ of $\mathrm{HAuCl}_{4}$, and a growth time of $1 \mathrm{~h}$ (at $120{ }^{\circ} \mathrm{C}$ ), $\mathrm{Au}_{0.60} \mathrm{Ag}_{0.40}$ NPs were obtained. Oleylamine was used as the surfactant and was readily removed after synthesis. The $\mathrm{Au}-\mathrm{Ag}$ nanoalloy showed compositional dependent plasmonic absorption, indicating their potential as optical probes for bioimaging.

Zhang et al. reported a multi-step procedure for the synthesis of highly monodisperse $\mathrm{Au}-\mathrm{Ag}$ NPs by a galvanic displacement process, using long chain alkyl amines for tuning the size distribution of Ag NP seeds. ${ }^{48}$ In a recent report, synthesis was carried out by the use of the corresponding $\mathrm{Au}(\mathrm{I})$ and $\mathrm{Ag}(\mathrm{I})$ dodecanethiolate complexes, with oleylamine as a solvent and a reducing agent to obtain $\mathrm{Au}-\mathrm{Ag}$ nanoparticles sizes ranging from 3 to $6 \mathrm{~nm} .{ }^{49}$ The strongly interacting capping agents (alkylthiolate ligands) were used to control the growth of the nanoparticles. 

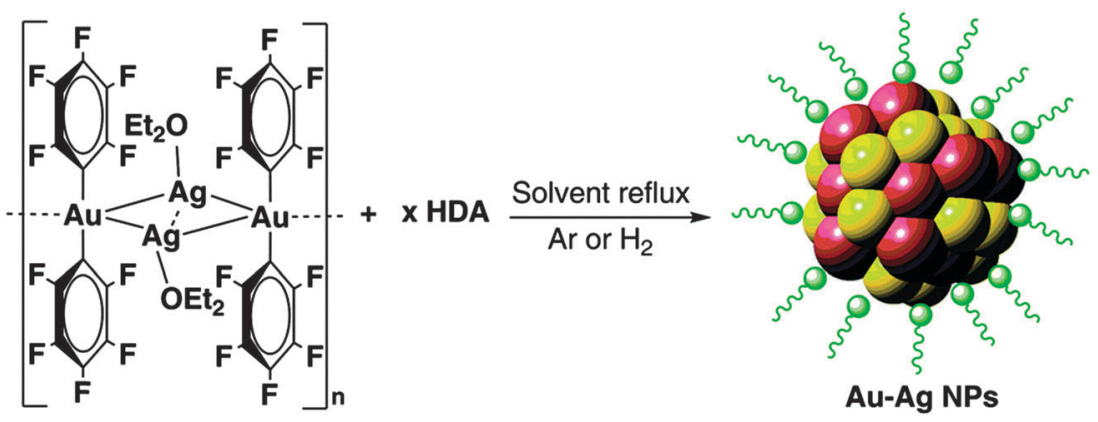

$$
\begin{gathered}
\text { HDA }=\mathrm{NH}_{2}-\left(\mathrm{CH}_{2}\right)_{15}-\mathrm{CH}_{3} \text { Orr } \\
x=1,2 \text { or } 4
\end{gathered}
$$

Fig. 3 Monodisperse Au-Ag nanoalloys prepared using decomposition of a bimetallic precursor and hexadecylamine (HDA) stabilizing agent. ${ }^{50}$ Reproduced from Ref. 50 with permission from The Royal Society of Chemistry.

It should be noted that when oleylamine is used as a solvent, random $\mathrm{Au}-\mathrm{Ag}$ compositions are obtained due to differences in reduction rates of the $\mathrm{Au}$ and $\mathrm{Ag}$ metal salts. Another commonly used stabilizing ligand is hexadecylamine (HDA). Monodisperse $\mathrm{Au}-\mathrm{Ag}$ alloy nanoparticles of different compositions are prepared via decomposition of the bimetallic precursor $\left[\mathrm{Au}_{2} \mathrm{Ag}_{2}\left(\mathrm{C}_{6} \mathrm{~F}_{5}\right)_{4}\right.$ $\left.\left(\mathrm{OEt}_{2}\right)_{2}\right]_{n}$ in an organic solvent, see Fig. $3 .^{50}$ The influence of reaction parameters (Au:Ag: $\mathrm{HDA}$ molar ratio, presence or absence of reducing agent and reaction temperatures) on the final size, shape and composition of the $\mathrm{Au}-\mathrm{Ag}$ NPs were investigated. It was shown that the different reaction parameters do not affect the size and the shape of the obtained Au-Ag NPs. However, these changes can provide variations of the Au content in the alloy NPs, leading to a tuning of the LSPR band.

(b) Physical synthesis. In recent years, laser ablation has emerged as a promising method for the synthesis of composition controlled alloy nanoparticles in liquids. This technique offers the flexibility to tune the stoichiometry of the alloys, ablated directly from their corresponding bulk targets (which could be alloys or single metals). Following the pioneering work of Lee et al., in the production of $\mathrm{Au}-\mathrm{Ag}$ alloy nanoparticles, ${ }^{51}$ this technique was further developed by Shafeev and his co-workers $^{52}$ and since then laser induced synthesis of $\mathrm{Au}-\mathrm{Ag}$ alloy nanoparticles has been reported widely. ${ }^{53}$ This method has proven to be an efficient pathway for the synthesis of pure ligand-free nanoparticles applicable in toxicity assays. ${ }^{54-57}$

It is worth noting that compared to chemical synthesis routes, the laser based synthesis method allows formation of homogeneous elemental distributions even on a single particle scale $^{58}$ in $\mathrm{Au}-\mathrm{Ag}$ alloy NPs, demonstrated by UV-vis spectroscopy as well as TEM-EDX. ${ }^{59}$ These findings indicate that the alloying process (elemental segregation) during laser synthesis is not solely dominated by surface oxidation, but also by the elemental composition from the ablated target.

Among other physical nanofabrication techniques, an interesting example was reported by Bok et al. to prepare $\mathrm{Au}-\mathrm{Ag}$ alloy nanorods with multiple LSPR modes by electrochemical deposition. ${ }^{60}$ Varying the proportional composition of two metals in a plating solution led to tunability of the resonance wavelength. (c) Biosynthesis. With the current drive to adopt "green" approaches to design environmentally benign materials and processes, the biosynthesis approach has proved advantageous in generating alloy nanoparticles. ${ }^{61,62}$ Biosynthesis methods, in contrast to most conventional synthesis methods, can be carried out at ambient conditions of temperature, $\mathrm{pH}$, and pressure. The biogenic entities secrete large amount of proteins leading to metal-ion reduction and morphology control. ${ }^{63}$ Additionally, the handling of microbial cultures and the downstream processing of biomass can be more straightforward to upscale to industrial levels and can have a lower lifecycle impact compared to synthetic methods. ${ }^{64}$ The NPs synthesized by biological approaches exhibit high bio-catalytic reactivity, and an enhanced conjugation between the enzyme and the corresponding metal ion due to the biological carrier matrix. ${ }^{65}$

It is now very well established that the biological systems such as microorganisms, plant extracts, and fungi can produce a variety of nanoparticles through biological pathways. ${ }^{66-68}$ For example, production of metal particles of different morphology through plant and leaf extracts, ${ }^{69}$ bacteria $^{70}$ and yeast ${ }^{71}$ for the reduction of toxic metals, application of biological templates, ${ }^{72}$ and use of different bacterial cells for the noble metals synthesis have been reported. ${ }^{73,74}$ Nanoparticle synthesis via the biological route occurs when the metal target ions from the microorganism's environment are reduced to element metal via the activity of enzymes generated by the cell or cellular extract. Biosynthesis of nanoparticles can be either intra or extracellular. ${ }^{75}$ For the intracellular method the nanoparticles are fabricated 'intra' or 'in' the microbial cells by injecting the metal ions in the presence of enzymes. ${ }^{76}$ On the other hand, extracellular synthesis of nanoparticles requires adsorption of the metal ions on the surface of the cells and thus reduction of ions in the presence of enzymes. ${ }^{77}$ The extracellular method is considered to be more efficient and economical with less complicated processing as compared to intracellular synthesis which requires additional steps such as ultrasound treatment or reaction with suitable detergents to release the nanoparticles from cells during purification. ${ }^{78}$

Mukherjee et al. demonstrated the use of eukaryotic organisms such as fungi in nanomaterials synthesis; for instance, 
intracellular fabrication of $\mathrm{Au}$ and $\mathrm{Ag}$ alloy NPs using Verticillium sp. ${ }^{79,80}$ In addition, fungus Fusarium oxysporum was successfully employed for the extracellular synthesis of $\mathrm{Au}$ and $\mathrm{Ag}$ nanoparticles. ${ }^{81}$ Synthesis of bimetallic $\mathrm{Au}-\mathrm{Ag}$ nanoalloy by fungus Fusarium oxysporum has been reported by other workers ${ }^{82}$ and the role of $\mathrm{NADH}$ cofactor has been highlighted in controlling the composition of the Au-Ag nanoalloys. The synthesis of coreshell $\mathrm{Au}-\mathrm{Ag}$ nanoalloys from other fungal strains such as Fusarium semitectum has also been reported. ${ }^{83}$ Aqueous solutions of chloroaurate ions for $\mathrm{Au}$ and $\mathrm{Ag}$ ions (1:1 ratio) were treated with an extracellular filtrate of Fusarium semitectum biomass for the formation $\mathrm{Au}-\mathrm{Ag}$ nanoalloys. This particular approach is significant due to the feasibility of obtaining nanoparticle colloids with stability over periods of weeks. ${ }^{83}$

$\mathrm{Au}-\mathrm{Ag}$ nanoalloy synthesized using yeast cells has also been demonstrated. ${ }^{84}$ Chemical analysis of the bioorganic molecules secreted by the microorganisms indicated that reduction of the metal ions was performed by enzymatic reactions and that the metal nanoparticles were stabilized by surface-bound proteins. Transmission electron microscopic characterization indicated that the Au-Ag alloy nanoparticles were mainly synthesized via an extracellular approach and generally existed in the form of irregular polygonal nanoparticles, see Fig. 4.

\subsection{Preparation of FeO core shell plasmonic-oxide nanocomposites}

In this section the development of core shell plasmonic-oxide nanocomposite materials (containing separate domains) for biomedical sensing is presented with a focus on magneticplasmonic $\mathrm{Fe}_{x} \mathrm{O}_{y} @ \mathrm{Au}$ (core@shell) and $\mathrm{Fe}_{x} \mathrm{O}_{y} @ \mathrm{SiO}_{2} @ \mathrm{Au}$ nanocomposites. The challenges in their preparation and their advantages for optical detection of biomolecules will be described. Magnetic nanoparticles (MNPs) of iron oxide are favoured because of their ease of synthesis, chemical stability, relatively high saturation magnetisation, superparamagnetism

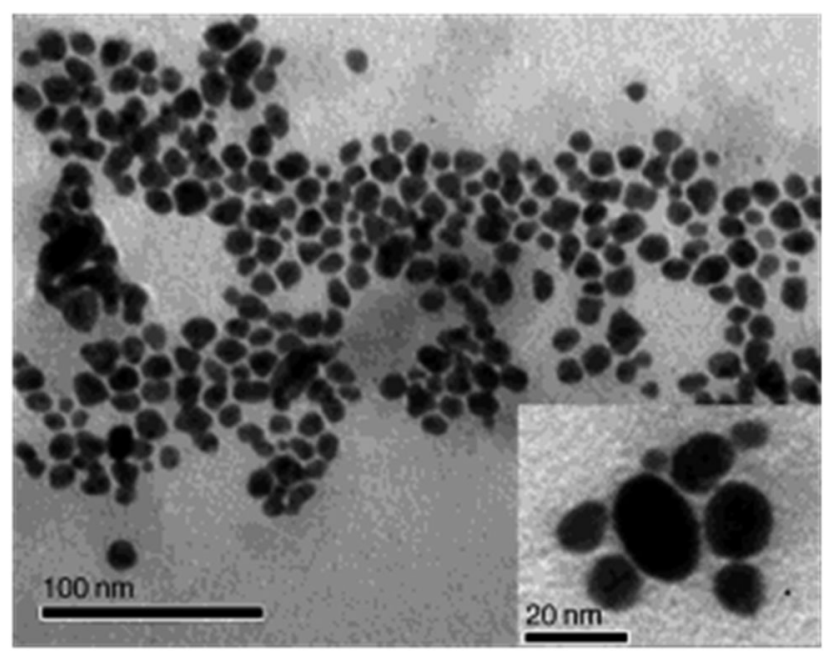

Fig. 4 TEM images of $\mathrm{Au}-\mathrm{Ag}$ nanoparticles formed by reaction of a mixture of $1 \mathrm{mM} \mathrm{HAuCl}_{4}$ and $1 \mathrm{mM} \mathrm{AgNO}_{3}$ with $60 \mathrm{~g}$ Fusarium oxysporum wet biomass for $96 \mathrm{~h}^{82}$ Reproduced from Ref. 82 with permission from John Wiley \& Sons, Inc. (which contributes to good long term stability) and low toxicity. In practice it is difficult to distinguish crystallographically between the magnetic phases usually formed, $\mathrm{Fe}_{3} \mathrm{O}_{4}$, and $\gamma-\mathrm{Fe}_{2} \mathrm{O}_{3}$, as they have very similar magnetic properties, hence in this paper they are referred to as $\mathrm{FeO}$ except where the referenced authors are very clear in their attribution.

A wide range of approaches have been adopted for the preparation of the $\mathrm{Fe}_{x} \mathrm{O}_{y} @ \mathrm{Au}$ nanocomposites. While it is not possible to review all of the synthetic methods that have been used, some key illustrative examples are presented here. The $\mathrm{Fe}_{x} \mathrm{O}_{y}$ core can be prepared by aqueous (usually co-precipitation) methods, or by thermal decomposition. The gold layer is prepared by attaching $\mathrm{Au}$ NP seeds followed by reduction of $\mathrm{HAuCl}_{4}$, or sometimes in a single reductive step without using the seed attachment step. From a synthetic perspective a major challenge in the formation of the plasmonic shell is preventing autocatalytic Au reduction/growth, which can result in very thick shells and/or sub-populations of Au NPs. The situation is exacerbated by the mismatch in surface energy between $\mathrm{Au}$ and $\mathrm{Fe}_{x} \mathrm{O}_{y}$, which reduces wetting by $\mathrm{Au}$ of the $\mathrm{Fe}_{x} \mathrm{O}_{y}$ surface. This issue can be partially addressed kinetically through control of the feed ratio, ${ }^{21}$ or after synthesis through extensive centrifugation. ${ }^{21,30}$ One interesting approach to control the surface chemistry prior to gold addition is to passivate the $\mathrm{FeO}$, usually with a silica or alkyl silane layer.

For MNPs prepared by the aqueous route, the $\mathrm{Fe}_{x} \mathrm{O}_{y}$ surface is usually passivated prior to reduction of $\mathrm{Au}$ in water. This can be achieved by surface functionalisation, for instance with triethoxysilane (TEOS) to produce a thick silica layer. ${ }^{31,85}$ In both the examples, Au seeds were used in a two step plasmonic layer preparation. In the latter case ${ }^{85}$ the $\mathrm{Fe}_{x} \mathrm{O}_{y}$ component was c. $10 \mathrm{~nm}$ and the Au layer was thin, $<10 \mathrm{~nm}$. ICP analysis demonstrated a composition of $44 \% \mathrm{Fe}_{3} \mathrm{O}_{4}, 8 \% \mathrm{Si}$ and $48 \% \mathrm{Au}$, which is consistent with the proposed structure. The advantages of outer $\mathrm{Au}$ layers over solid nanoparticles for tuning the optical response and for photothermal ablation were identified. However the silica content was rather high and as the authors note each particle probably contains multiple cores, demonstrating some uncertainty about the structure/structure distribution formed.

In the former example, ${ }^{36}$ the silica layer was again thick (85 nm), with a $30 \mathrm{~nm}$ Au shell, the $\mathrm{Fe}_{x} \mathrm{O}_{y}$ NPCs comprising $c$. $2 \%$ by wt of the total the nanocomposites were $c .170 \mathrm{~nm}$ in size. It is apparent that, despite the findings in the latter work, in several other cases there are significant fractions of magnetic-only and plasmonic only particles present. In TEM micrographs the $\mathrm{z}$-contrast difference between $\mathrm{Au}$ and $\mathrm{Fe}$ should be sufficient for unambiguous confirmation of nanoscale mixing, so a proper attribution should usually be possible. $\mathrm{FeO}$ passivation has also been reported for $40 \mathrm{~nm}$. $\mathrm{Fe}_{x} \mathrm{O}_{y} \mathrm{NP}$ clusters achieved using bi-functional ligands such as MPEG$\mathrm{SH}^{21}$ to produce a thin $\mathrm{Au}$ shell (with $\mathrm{Au}: \mathrm{Fe}$ of $0.15: 1$ ). By controlling the kinetics of Au layer growth (no Au seeds) while maintaining very low Au content, secondary nucleation could be avoided and the morphology of the layer could be altered from being 'partial' to 'knobbly' to 'smooth'.

In many cases MNPs produced by the thermal route are surface passivated and phase transferred into water for the gold 
coating. Bi-functional silanes such as aminopropyltriethoxysilane (APTES), which form a monolayer (or at least a thin layer) with an outer amino group ensuring water dispersibility are typically used. In one notable case ${ }^{86}$ the exchange of the surface layer of oleic acid/octylyamine present after the thermal reaction was reported. The Au layer was again grown in two steps, with initial attachment of $2 \mathrm{~nm}$ Au NPs. This approach could be used to take advantage of the improved crystallinity, size control and monodispersity of the $\mathrm{Fe}_{x} \mathrm{O}_{y}$ NPs from the thermal route. Aside from the advantage of size control this is the more likely route to colloidal stability in aqueous or biological environments, which ultimately requires steric as opposed to electrostatic stabilisation of the nanocomposite.

Other bi-functional ligands can also be used. In an interesting report, ${ }^{31}$ highly uniform $18 \mathrm{~nm}$ MNPs, prepared by the Colvin method $^{87}$ to ensure uniformity followed by a variation on the thermal decomposition method to ensure crystallinity ${ }^{38}$ were ligand exchanged with TMAOH for phase transfer into water. Passivation with mercapto-undecanoic acid (MUA) was then applied to prevent localised nucleation (and hence formation of a dumbbell structure) before initial attachment of $1.5 \mathrm{~nm} \mathrm{Au}$ seeds and subsequent reduction of $\mathrm{HAuCl}_{4}$. The authors noted improved colloidal stability as compared to the use of silanes. One could speculate, on the basis of the report noted above, ${ }^{21}$ that a single step reduction of $\mathrm{HAuCl}_{4}$ might suffice, given the pendant thiol present in both cases. However, identifying the exact conditions to control the layer thickness and shape would be challenging.

Thermal decomposition methods have also been used for preparing both the $\mathrm{Fe}_{x} \mathrm{O}_{y}$ core and the Au shell by sequential decomposition of iron and then gold precursors in situ in nonaqueous media. ${ }^{35}$ In this case the nanocomposites were processed by centrifugation and subsequently deposited as thin films by molecularly mediated assembly for detection applications. In a very well-known example from the Sun group ${ }^{37}$ multiple plasmonic layers were deposited and the non-aqueous suspensions were dried and resuspended with citrate and CTAB to form a stable aqueous suspension, presumably with a stabilising СTAB bilayer. In both these cases the $\mathrm{Fe}_{x} \mathrm{O}_{y}$ surface was not passivated before reduction of $\mathrm{HAuCl}_{4}$ in organic media (no $\mathrm{Au}$ seeds), using oleylamine as the 'gentle' reducing agent in the latter case. This study ${ }^{37}$ is a particularly elegant demonstration of the tuning of the plasmonic response by stepwise addition of increasingly thick layers $\mathrm{Au}$ or $\mathrm{Ag}$ to $\mathrm{Fe}_{x} \mathrm{O}_{y} @ \mathrm{Au}$ NPs. A progressive red or blue shift of the $\lambda_{\text {spr }}$ value was observed of up to $27 \mathrm{~nm}$ (red) on increasing the Au shell thickness by 2.5 to $3 \mathrm{~nm}$, and of up to $33 \mathrm{~nm}$ (blue) with a similar increase in the $\mathrm{Ag}$ shell thickness, on the gold coated cores. The influence of core permittivity and size on the plasmonic tunability has been analysed. ${ }^{86} \mathrm{~A}$ comprehensive theoretical treatment demonstrated the feasibility of geometric plasmon tunability over a range of core permittivity's and shell thicknesses. The method also enables extraction of the dielectric properties of the core from the plasmonic response, under ideal conditions.

As an interesting alternative, the Sun group have prepared dumbbell shaped $\mathrm{Au}-\mathrm{Fe}_{3} \mathrm{O}_{4}$ NPs by epitaxial growth of iron oxide on Au NPs, by decomposition of $\mathrm{Fe}(\mathrm{CO})_{5}{ }^{88}$ In another prominent article the layered approach was taken a step further ${ }^{89}$ to produce a silane@FeO@Au nanocomposite, with a quasi-spherical silane core surface decorated with silica stabilised FeO NPs surrounded by a thin Au shell (1-3 nm Au NPs were bound initially). While interesting chemically, and promising from the perspective of high selective DNA detection (DNA melting curves were show), it is unlikely that the magnetic content is sufficiently high for magnetophoretic control.

\section{Bio-sensing applications with $\mathrm{Au}-\mathrm{Ag}$ and $\mathrm{Fe}_{x} \mathrm{O}_{y}$ (Au nanoalloys}

\section{(a) Nanoalloys in SERS biosensing applications}

Raman based diagnostics of tissue and cell (prokaryotic and eukaryotic) samples is reaching maturity for a broad range of pathogenic and non-pathogenic disease states. ${ }^{90-92}$ Indeed, there are now numerous commercial companies offering clinical diagnostics based on Raman spectroscopy. Applications of SERS as a diagnostic tool are however still evolving. Biomarker detection is probably one of the most active areas of SERS bioanalytical research. One of the most widely implemented approaches is incorporation of SERS into sandwich-style bioassays, where a biomolecular recognition moiety e.g. oligonucleotide, aptamer, peptide or antibody is assembled on the SERS substrate to target the analyte. ${ }^{93}$ Frequently the SERS substrate is a nanoparticle or in some instances a macroscopic SERS interface, e.g. roughened gold or nanofabricated array on which the capture agent is assembled. There are two relatively common formats; in the first the target is captured between a capture and reporter strand motif, both bound to SERS substrates, e.g. capture and probe DNA, and detection occurs due to the enhanced signal at the target as it is sandwiched between two plasmonic nanoparticles or a particle and SERS active substrate on which the capture strand is immobilised. The Raman signature of the target is the analytical signature of interest, and discrimination is made on the basis of the Raman fingerprint of the target. ${ }^{94}$ In an alternative and much more common approach, the signature that is recorded is that of a SERS or SERRS (surface enhanced resonance Raman) active dye which is bound directly to the probe motif or to a nanoparticle (e.g. core shell structure) on the probe motif. Examples of this approach have been used with antibodies and particularly widely with oligonucleotides across a broad range of disease states, and this format can be either solution based or interfacial where one of the SERS substrates is a macroscopic surface. Very low limits of detection for target analytes have been reported using this approach. ${ }^{95}$

Conventional Raman spectroscopy, is often implemented via microscopy or for in vivo diagnostics with fibre optic modality which is often non- or minimally invasive. Although Raman spectra of composite biological matrices can be challenging, robust chemometric analysis of the complicated but characteristic spectra have really advanced this field toward clinical and point of care applications. Research activity in the field of SERS applied to diagnostics is extensive and a detailed 
review and historical perspective of this is beyond the scope of the present article. ${ }^{96}$ Instead the reader is directed to a number of insightful reviews which have been published recently. ${ }^{97-99}$ Whereas, the vast majority of diagnostic SERS applications have focussed on single metal species, metal composites and nanoalloys are being increasingly applied in SERS. ${ }^{100-102}$ The advantages of using nanoalloys in this context are the possibility of generating higher signal enhancement and improving biocompatibility. ${ }^{103-107}$ This is particularly the case in applying silver to bio diagnostics. Silver can yield very high Raman enhancements and toxicity induced by silver can be mitigated by coating silver in gold. Moreover, unlike pure $\mathrm{Ag}$ or $\mathrm{Au}$ NPs, $\mathrm{Au}-\mathrm{Ag}$ alloy NPs exhibit higher stability and surface enhancement ${ }^{108}$ which can potentially be applied to living cell imaging. ${ }^{109}$ In the case of the magneticplasmonic materials the presence of the magnetic component provides possibilities for concentrating the particles to obtain the most intense Raman response from the probes. In a clinical setting such magnetic 'pre-concentration' could also be used to isolate the modified particles from background medium. ${ }^{110}$

Herein, an overview is presented of the application of nanoalloys ( $\mathrm{Au}-\mathrm{Ag}$ and magnetic plasmonic) in SERS for biodiagnostics and sensing with selected approaches from recent literature.

\section{(b) Plasmonic Au-Ag nanoparticle systems}

As discussed above, optical responses for $\mathrm{Au}-\mathrm{Ag}$ NPs depend predominantly on their composition and configuration (alloy and core-shell). The plasmon absorption band of $\mathrm{Au}-\mathrm{Ag}$ NPs lies at an intermediate position between pure Au and Ag NPs and can similarly lead to amplification of SERS signal from surface localized molecules. ${ }^{111}$ Indeed superior SERS performances of $\mathrm{Au}-\mathrm{Ag}$ alloy nanoparticles have been reported. In view of this, SERS application of different configuration of $\mathrm{Au}-\mathrm{Ag}$ NPs is presented together with an insight on their performance.

Core@shell structures. In an early example of a nanoalloy applied in a SERS sandwich assay, Tian and co-workers ${ }^{101}$ described fabrication of Ag@Au (core@shell) NPs labelled with monoclonal goat anti mouse antibodies for IgG for immunorecognition and with thiophenol as the Raman reporter. Synthesis of Ag@Au NPs was carried out by the seed-growth method. The captured antibody was assembled onto a planar silver coated glass surface. It was found that the SERS activity of aggregated colloids depends significantly on the molar ratio of Ag to Au. About 10 times more intense SERS activity was recorded with the increase of the $\mathrm{Au}$ molar fraction in $\mathrm{Ag}_{\text {core }} \mathrm{Au}_{\text {shell }}$ compared to Ag colloids.

Recently, application of Au@Ag core-shell NPs as a hydrogen peroxide $\left(\mathrm{H}_{2} \mathrm{O}_{2}\right)$ biosensor was reported with hemoglobinchitosan-1-butyl-3-methyl-imidazolium tetrafluoroborate (HbCHIT-BMIM $\times \mathrm{BF}_{4}$ ) composite film. ${ }^{21}$ The fabricated biosensor displayed a detection limit of $4 \times 10^{-7} \mathrm{M}(\mathrm{S} / \mathrm{N}=3)$ and good electrocatalytic activity was found for reduction of $\mathrm{H}_{2} \mathrm{O}_{2}$ in the range from $1.0 \times 10^{-6}$ to $1.0 \times 10^{-3} \mathrm{M}$. The excellent detection limit was attributed to the synergistic effect of the Au@Ag coreshell NPs and Hb-CHIT-BMIM $\times \mathrm{BF}_{4}$ (with a Michaelis-Menten constant of $\left(K_{\mathrm{M}}\right) 4.4 \times 10^{-4} \mathrm{M}$, confirming high affinity). This study opens up new opportunities for the design of enzymatic biosensors.

Bimetallic surfaces. It has been shown that the biosensing sensitivity of mono-metallic surface plasmon resonance is significantly improved by using bi-metallic nanoparticles (Au/Ag NPs) coated on solid functionalized supports (for instance, glass substrates) before specific immobilization of biomolecules. Vo-Dinh's group reported improved SERS enhancement compared to a single gold film while maintaining signal stability. ${ }^{112}$ This group further advanced the approach of 'metal film over nanospheres' (MFON) by applying Ag-Au alloy films over polystyrene spheres (430 nm diameter) for their SERS substrate onto which DNA sequence for dengue virus was analysed. ${ }^{113}$ The substrates were prepared by using $5 \mathrm{~nm}$ Ti over the PS array, presumably to adhere the metal to the spheres, over which $100 \mathrm{~nm}$ of $\mathrm{Ag}$ and of $\mathrm{Au}$ were deposited (see Fig. 5). Again, the signal was transduced through changes to SERS intensity instigated by altering distance between the SERS reporter and the substrate. In this case the distances were shortened and SERS switched on hybridization of the target which caused the immobilised DNA to form hairpin structures. Taking into account the number of molecules under the exciting laser irradiation area, the authors estimated they were able to detect attomole quantities of the single stranded target DNA. A similar approach has been applied to SERS detection of whole pathogens using nanoalloys. For example Waluk and his group $^{114}$ reported that an $\mathrm{Au}-\mathrm{Ag}$ bimetallic SERS surface can provide strong Raman enhancement, with high reproducibility, for identifying the pathogenic bacteria, E. coli, S. enterica and $S$. epidermidis from blood samples. The SERS spectra of these four bacterial species were obtained on a vancomycin-coated hybrid surface, see Fig. 6. Vancomycin is an antibiotic useful for the treatment of a number of bacterial infections. Thus, vancomycin coated SERS substrate was utilized to selectively captured bacteria from blood samples and also increased the Raman signal in contrast to the bare surface. The results show that the intensity of SERS signals from the vancomycin-coated substrate in comparison with the bare substrate is $\sim 8$ times higher for S. epidermidis (Fig. 6) and B. megaterium, $\sim 4$ times higher for $S$. enterica, and $\sim 5$ times for $E$. coli. Higher signal intensity for $S$. epidermidis and B. megaterium than for E. coli and S. enterica was attributed to the fact that vancomycin is more effective against Gram positive than Gram-negative bacteria.

Alloy nanoparticles. A study by Intartaglia et al. ${ }^{115}$ reported SERS investigations on crystal violet (CV) chemisorbed on the laser generated ligand-free $\mathrm{Au}-\mathrm{Ag}$ NPs at different laser wavelengths. CV is an effective stain used for highlighting acidic components of tissues especially for nerve tissue types. A SERS enhancement factor in this case of about $5.7 \times 10^{5}$ was reported compared with the flat $\mathrm{Au}-\mathrm{Ag}$ surface.

Moreover, the use of different $\mathrm{Au}-\mathrm{Ag}$ alloy nanoprobes in combination with the pure gold nanoprobes has allowed creation of a multiplex DNA biosensor. ${ }^{116}$ Nanoparticles with different noble metal compositions ( $\mathrm{Au}-\mathrm{Ag}$ ) were prepared in an alloy configuration and were functionalized with thiol-modified 


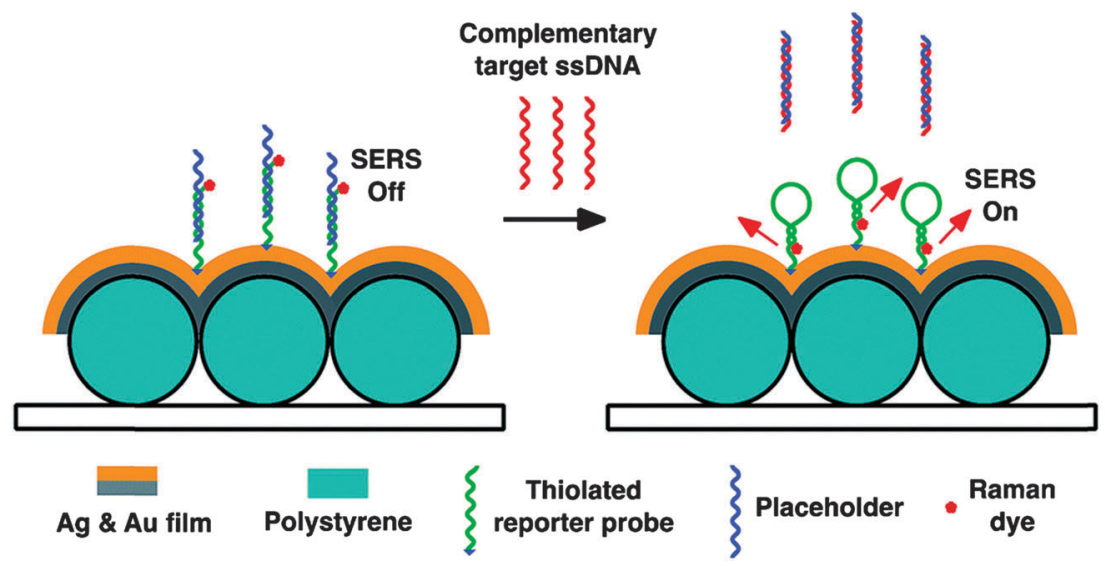

Fig. 5 Illustration of the label-free complementary target DNA detection scheme, Vo-Dinh et al. ${ }^{113}$ Reproduced from Ref. 113 with permission from The Royal Society of Chemistry.
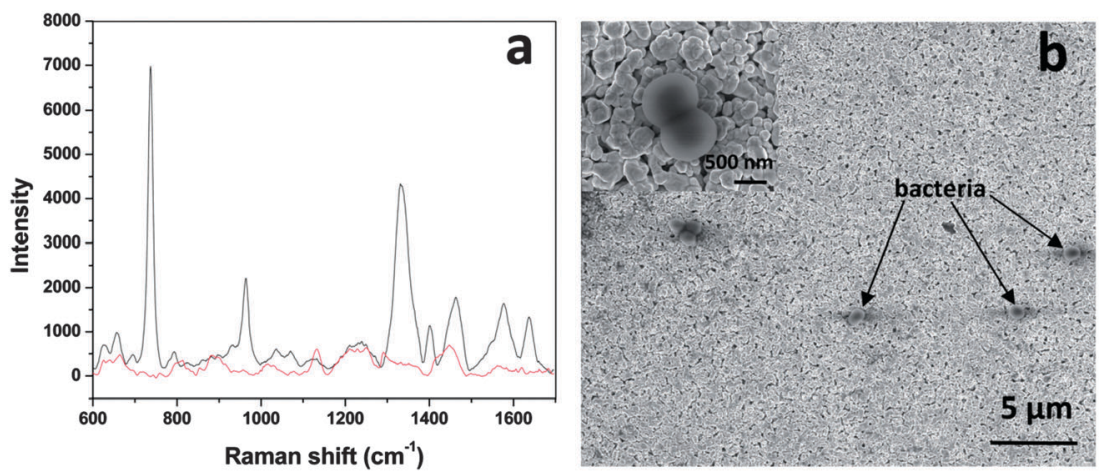

Fig. 6 (a) SERS spectra of healthy human blood (red) and S. epidermidis spiked human blood (black) on the vancomycin-coated Ag-Au hybrid surface. (b) SEM image of $S$. epidermidis selectively captured from blood components on the hybrid substrate. The inset shows a magnified view of S. epidermidis. ${ }^{114}$ Reproduced from Ref. 114 with permission from The Royal Society of Chemistry.

ssDNA (nanoprobes). These nanoprobes were then used for the simultaneous specific identification of several mRNA targets involved in cancer development, thus enabling one pot multicolour detection of cancer expression. The different metal composition in the alloy yield different "colors" that can be used as tags for identification of a given target. Subsequently the multicolour nanoprobes were used for molecular recognition of a number of differently spliced variants of relevant genes (including some involved in chronic myeloid leukemia; BCR, ABL, BCR-ABL fusion product).

Cai et al., ${ }^{117}$ in a similar approach reported on the use of aptamer modified $\mathrm{Au}-\mathrm{Ag}$ nanostructures for detection of human breast cancer MCF-7 cells using SERS. The nanoparticles were modified with both aptamer and Rhodamine $6 \mathrm{G}$ which was used as a Raman marker, and the authors found that their probes discrimination of MCF-7 cells from normal breast cells in vitro. Furthermore, because of their high NIR cross section, the particles could be for selective photothermal destruction of the cancerous cell line.

Cao et al. ${ }^{118}$ described the application of bimetallic NPs to develop a specific colorimetric DNA biosensor based on oligonucleotide functionalized AuAg-nanoprobes for the specific detection of a DNA sequence from TP53-a gene involved in cancer development. This study provided a successful alternative detection method (colorimetric change) different from the conventional $\mathrm{Au}$ system. This could be advantageous for monitoring of multiple oligonucleotide targets in one sample, an essential requirement for clinical analysis in multicolour immunoassays.

Zheng et al. reported $\mathrm{Au}-\mathrm{Ag}$ alloy nanoparticles biosynthesized by yeast cells applied to fabrication of a sensitive electrochemical vanillin sensor. ${ }^{84}$ Under optimal working conditions, the oxidation peak current of vanillin at the sensor linearly increased with its concentration in the range of $0.2-50 \mu \mathrm{M}$ with a detection limit of $40 \mathrm{nM}$. This vanillin sensor was successfully applied to the determination of vanillin from vanilla bean and vanilla tea samples, suggesting that it may have practical applications in natural product monitoring. These electrochemical investigations revealed that the vanillin sensor based on $\mathrm{Au}-\mathrm{Ag}$ alloy nanoparticles, coupled with a modified glassy carbon electrode (GCE), provided a five-fold enhancement in electrochemical response compared to bare GCE.

\section{(c) Magnetic-plasmonic@Au nanoalloys}

In the last few years the literature on magnetic/plasmonic materials for sensing or detection has expanded rapidly. It is 

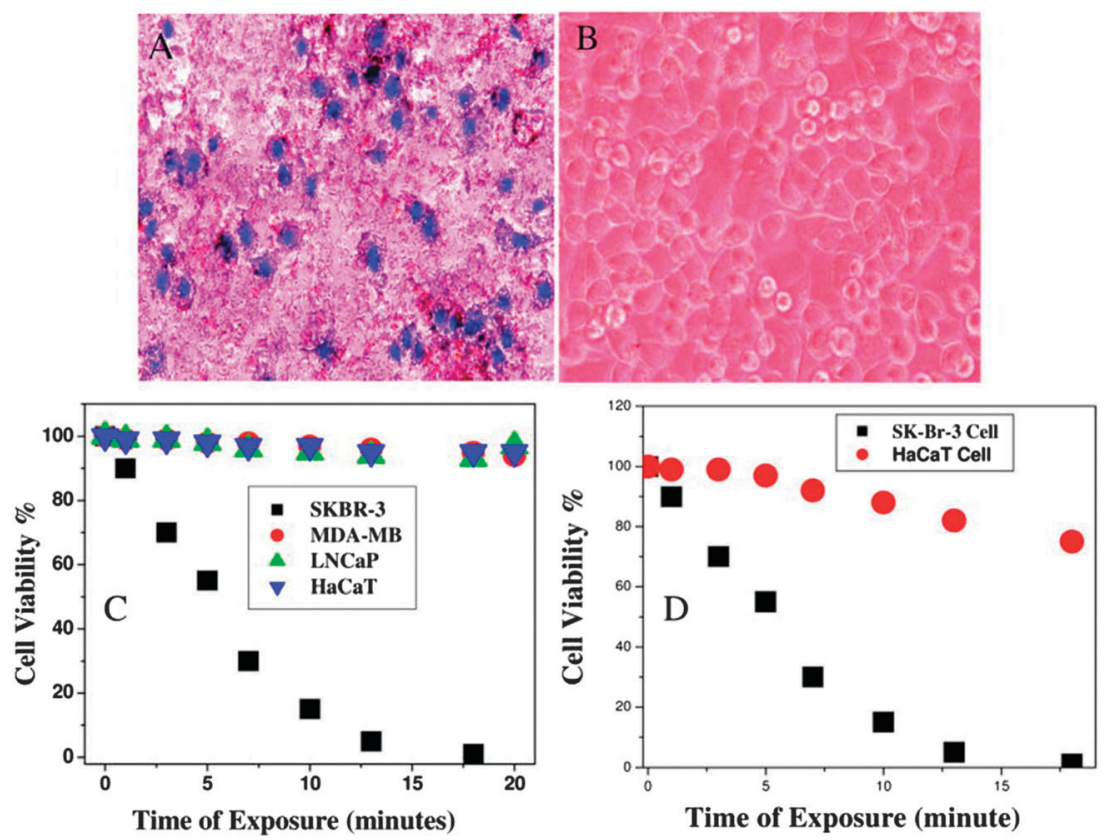

Fig. 7 Upper bright field inverted microscopy of (left) aptamer-conjugated $\mathrm{Fe}_{3} \mathrm{O}_{4}$ @A Au NPs, attached to SK-BR-3 breast cancer cells after irradiation, (right) bright-field inverted images of SK-BR-3 cells alone after irradiation followed by staining with trypan blue. Lower; cell viability when S-6 aptamerconjugated $\mathrm{Fe}_{3} \mathrm{O}_{4}$ @Au NPs were attached and irradiated (left) SK-BR-3, MDA-MB, and HaCaT cells, (right) SK-BR-3 and HaCaT cell mixtures (1:0.01). Reprinted with permission from ref 26 (Z. Fan, M. Shelton, A. K. Singh, D. Senapati, S. A. Khan and P. C. Ray, ACS Nano, 2012, 6(2), 1065-1073) Copyright (2012) American Chemical Society.

not possible to present an exhaustive review within this article, so a few noteworthy recent examples are presented to provide an indication of the current state-of-the-art and the potential of these materials. In a recent report, ${ }^{40} \mathrm{a} \mathrm{Fe}_{3} \mathrm{O}_{4} @ \mathrm{SiO}_{2} @ \mathrm{Au}$ nanocomposite suspension for combined magnetic responsiveness, biosensing and bioimaging was produced. Thermal FeO synthesis was applied, with the Stober method used to add TEOS, and subsequently APTES, the Au coating was added in a single step to prepare NPs comprising a $74 \mathrm{~nm}$ FeO cluster core, $20 \mathrm{~nm}$ thick $\mathrm{SiO}_{2}$ layer and $30 \mathrm{~nm}$ Au shell. Two-photon luminescence (TPL) 3D-imaging of single cells, NIR SERS and cell collection by magnetic separation were demonstrated. Magnetically directed assembly of particle chains was also shown in suspension which further increased the TPL intensity by an order of magnitude, apparently due to plasmon coupling.

The Ray group recently reported ${ }^{26}$ an aptamer-conjugated $\mathrm{Fe}_{3} \mathrm{O}_{4} @ \mathrm{Au}$ nanocomposite (50 nm hydrodynamic size) suspension for targeted imaging/magnetic separation of selected cells from a mixture of different cancer cells, see Fig. 7. The materials were prepared by the Massart (co-precipitation) route, with TMAOH coating and multiple Au reductions to produce a thick shell for binding thiol-modified Cy3-bound S6 aptamers specific to (HER2+) SKNBR-3 cells. With a binding density of $>100$ aptamers/NP and specific uptake it was reported that irradiation for 10 minutes $\left(670 \mathrm{~nm}, 2.5 \mathrm{~W} \mathrm{~cm}^{-2}\right)$ resulted in selective irreparable cellular damage to most (apparently $>99 \%$ ) of the targetted cells with $>93 \%$ viability of the remaining HER2-cell types. It was anticipated that the specificity would increase in clinical settings due to better heat dissipation.
More recently the Ray group reported ${ }^{29}$ multifunctional popcorn-shaped Fe@Au nanocomposite $(20 \mathrm{~nm}$ Fe metal core size) cystamine-linked with M3038 antibodies (>100 AB/NP). The high curvature Au tips provided a large SERS enhancement, producing sensitivity as low as 100 colony forming units per $\mathrm{mL}$ of MDR bacteria, which could enable label-free SERS imaging. Targeted separation and selective and irreparable photothermal (670 $\mathrm{nm} 1.5 \mathrm{~W} \mathrm{~cm}^{2}, 10 \mathrm{~min}$ ) cellular damage to M308+ multidrug resistant Salmonella DT104 was demonstrated.

Cancer cell separation enabled by antibody targeted SERS and fluorescence dual-encoded magnetic nanoprobes has recently been reported using an interesting NP assembly strategy. ${ }^{119}$ In this case, plasmonic nanorods (Au@Ag NRs) were attached to a magnetic $\mathrm{FeO}(250 \mathrm{~nm})$ core to enable a strong magnetophoretic effect. This in turn was silica coated (78 nm shell), with fluorescent quantum dots embedded in that component. The materials enabled rapid, specific cancer cell separation and may have potential for high-throughput analysis.

\section{Concluding remarks}

This review presents an overview of the various chemical, physical and biosynthesis methods for synthesis of $\mathrm{Au}-\mathrm{Ag}$ nanoalloys and FeO@Au nanocomposites and their application in bio-sensing. In the case of Ag-Au nanoalloys, the use of coreshell structures allows use of the well-established $\mathrm{Au}$-thiol chemistry for binding biospecies. ${ }^{118}$ However, this arrangement requires cumbersome synthesis, in part because the controlled 
deposition of $\mathrm{Au}$ over $\mathrm{Ag}$ is difficult to achieve due to galvanic displacement. ${ }^{126}$ Additionally, due to inter-layer metal diffusion at high temperatures, the optical properties of the core-shell nanoparticles can be compromised during synthesis. ${ }^{126}$ Nanoparticles with uniform or non-uniform atomic distribution can be more easily synthesized and can still exhibit remarkable and tunable optical properties, furthermore these NPs display a single plasmon absorption band in the visible spectrum, while core-shell NPs generally present a double plasmon band. ${ }^{127}$ However, the presence of surface $\mathrm{Ag}$ atoms can increase toxicity and reduce chemical stability. In the coming years the functionality of the different bimetallic nanoparticles arrangements will lead to informed decisions as to which different nanoalloy structures are the best for their associated analytical applications.

A wide range of viable synthetic approaches for the production of $\mathrm{Fe}_{x} \mathrm{O}_{y}$ @Au NPs are noted in this review. In the last few years the literature on magnetic/plasmonic materials for sensing or detection has also expanded rapidly. Some noteworthy recent examples presented above provide an indication of the current state-of-the-art. It is apparent that multifunctional magneto-plasmonic nanocomposites can be produced and their advantages can be realised in a laboratory setting. The most recent literature suggests that colloidal stability in biological fluids and non-toxicity, which are critical for any eventual application in vivo, are increasingly being addressed. However, this technology is not yet sufficiently mature to be found in commercial applications for separation, detection or regeneration.

Interestingly, for both $\mathrm{Au}-\mathrm{Ag}$ and $\mathrm{Fe}_{x} \mathrm{O}_{y} @ \mathrm{Au}$ nanoalloy/ nanocomposites presented in this review, a diverse range of synthesis methods continues to be applied, suggesting the absence of consensus on which approach is best. In the biosynthesis and physical synthesis routes, no additional reducing agents, such as hydrazine hydrate and trimethylamine borane (TMAB), or potentially toxic solvents, such as toluene, are required; providing a greener production process. A relatively small number of papers have been published on the biosynthesis of core@shell NP structures ${ }^{128}$ which may be due to the difficulty in achieving consistent control over nanoparticle size and shape via this route. This appears to be particularly relevant for intracellular synthesis, however, there may be possibilities for using sequential extracellular synthesis to fabricate core@shell structures. Today, chemical synthesis provides for more reproducible, uniform and controlled quantity of nanoalloy/nanocomposite production at scale than the alternatives. Hence from a quality control and performance evaluation viewpoint, the chemical route retains significant advantages.

Important challenges for production of nanoalloys include the control of the NP size and composition, as well as the prevention of NP aggregation. Stabilizing the surface by capping it with a shell of organic molecules can lead to controllable size, shape and surface properties. The majority of papers, including those discussed in this review, present the synthesis of isotropic spherical structures for nanoalloys. Very few methods have been reported for fabricating nanoalloys with a non-spherical shape. ${ }^{122}$ Given the unique physical and chemical properties that can be achieved from defined geometry of nanoalloys, ${ }^{123,124}$ it is likely that this possibility will be exploited in the near future. Density function theory (DFT) modelling could also be used to identify target structures for synthesis, with expected enhanced functionalities. ${ }^{125}$

An application of increasing importance for plasmonic nanoalloy substrates is in surface enhanced Raman spectroscopy as, due to its interfacial nature, SERS is inherently suited to chip based diagnostics. By combining SERS arrays for detection with microfluidic strategies for sample manipulation it is anticipated that in a short time advanced SERS detection of biomarkers in complex samples (including cells or even tissue) may be possible at low volume and with minimal off-chip preprocessing. In particular nanoalloys are likely to find growing applications as probes for plasmonically enhanced detection, a key component in innovative diagnostics, and even as agents in therapies. ${ }^{120,121}$ The most recent literature suggests that development of nanoalloy substrates in SERS diagnostics will be driven by research into targeting, control of toxicity, and, once again, by the optimal nanocomposite composition and architecture for the actual applications.

In conclusion, the development of plasmonic nanoalloys and nanocomposites is gradually moving from fundamentals and proof of concept studies, which have shown exciting potential, towards implementation. We suggest that success in that activity will require more detailed performance comparisons to be made between alternative nano-architectures and, in time, between alternative devices. This will first require the establishment of standards, or at least of agreed norms, for evaluating these novel materials for the identified fields of use.

\section{Acknowledgements}

Authors acknowledge and thank the financial support of this work from Science Foundation Ireland (SFI) under Grant Number 12/IA/1576 and COST Action Nanoalloy MP0903.

\section{References}

1 R. C. Cammarata, Nanocomposites, in Introduction to Nanoscale Science and Technology, ed. M. Ventra, S. Evoy and J. R. Heflin, Springer, 2004.

2 S. Xiong, W. Qi, B. Huang and M. Wang, ChemPhysChem, 2011, 12, 1317.

3 G. Rossi, A. Rapallo, C. Mottet, A. Fortunelli, G. Barcaro and R. Ferrando, Phys. Rev. Lett., 2004, 93, 105503.

4 F. Balleto, C. Morret and R. Ferrando, Phys. Rev. Lett., 2003, 90, 135504.

5 A. M. Molenbroek and J. K. Norskov, J. Phys. Chem. B, 2001, $105,5450$.

6 H. Yasuda and H. Mori, Phys. Rev. Lett., 1992, 69, 3747.

7 H. Portales, L. Saviot, E. Duval, M. Gaudry, E. Cottancin, M. Pellarin, J. Lermé and M. Broyer, Phys. Rev. B: Condens. Matter Mater. Phys., 2002, 65, 165422. 
8 D. Bochicchio and R. Ferrando, Nano Lett., 2010, 10, 4211.

9 F. Chen and R. L. Johnston, ACS Nano, 2008, 2, 165.

10 S. Darby, T. Mortimer-Jones, R. L. Johnston and C. Roberts, J. Chem. Phys., 2002, 116, 1536.

11 Large Clusters of Atoms and Molecules, ed. T. P. Martin, Kluwer, Dordrecht, 1996.

12 S. Giorgio, H. Graoui, C. Chapan and C. R. Henry, in Metal Clusters in Chemistry, ed. P. Braunstein, L. A. Oro and P. R. Raithby, Wiley-VCH, Weinheim, 1999, vol. 2, p. 1194.

13 R. L. Johnston, Philos. Trans. R. Soc. London, Ser. A, 1998, 356, 211.

14 L. Lu, H. Wang and Y. Zhou, et al., Chem. Commun., 2002, 144-145.

15 Y. Sun and Y. Xia, Analyst, 2003, 128, 686-691.

16 Y. Han, J. Jiang and S. S. Lee, et al., Langmuir, 2008, 24, 5842-5848.

17 K. A. Willets and R. P. Van Duyne, Annu. Rev. Phys. Chem., 2007, 58, 267.

18 L. M. Liz-Marzan, Langmuir, 2006, 22, 32.

19 Y. H. Choi, T. Kang and L. P. Lee, Nano Lett., 2009, 9, 85.

20 X. M. Lu, M. Rycenga, S. E. Skrabalak, B. Wiley and Y. N. Xia, Annu. Rev. Phys. Chem., 2009, 60, 167.

21 C. Ma, K. Liu, C. Ma and D. Chu, J. Chin. Chem. Soc., 2013, (4), 359-365.

22 M. D. Porter, R. J. Lipert, L. M. Siperko, G. Wang and R. Narayanana, Chem. Soc. Rev., 2008, 37, 1001-1011.

23 X. Yuan, Z. Luo, Y. Yu, Q. Yao and J. Xie, Chem. - Asian J., 2013, 8(5), 858-871.

24 S. Patskovsky, E. Bergeron, D. Rioux, M. Simar and M. Meunier, Analyst, 2014, 139, 5247-5253.

25 J. Lim and S. A. Majetich, Nano Today, 2013, 1, 98-113.

26 Z. Fan, M. Shelton, A. K. Singh, D. Senapati, S. A. Khan and P. C. Ray, ACS Nano, 2012, 6(2), 1065-1073.

27 R. Sensenig, Y. Sapir, C. MacDonald, S. Cohen and B. Polyak, Nanomedicine, 2012, 7(9), 1425-1442.

28 P. Arora, A. Sindhu, N. Dilbaghi, A. Chaudhury, G. Rajakumar and A. Rahuman, J. Cell. Mol. Med., 2012, 16(9), 1991-2000.

29 Z. Fan, D. Senapati, S. A. Khan, A. K. Singh, A. Hamme, B. Yust, D. Sardar and P. C. Ray, Chem. - Eur. J., 2013, 8, 2839-2847.

30 C. Schmidtke, H. Kloust, N. G. Bastus, J. Merkl, H. Tran, S. Flessau, A. Feld, T. Schotten and H. Weller, Nanoscale, 2013, 5, 11783.

31 J. Lim, A. Eggeman, F. Lanni, R. D. Tilton and S. A. Majetich, Adv. Mater., 2008, 20, 1721-1726.

32 D. Lopez, I. Cendoya, F. Torres, J. Tejada and C. Mijango, J. Appl. Polym. Sci., 2001, 82, 3215.

33 K. Raj, B. Moskowitz and R. Casciari, J. Magn. Magn. Mater., 1995, 149, 174-180.

34 H. Zeng, J. Li, Z. L. Wang, J. P. Liu and S. Sun, Nano Lett., 2004, 4, 187.

35 L. Wang, J. Luo, Q. Fan, M. Suzuki, I. S. Suzuki, M. H. Engelhard, Y. Lin, N. Kim, J. Q. Wang and C. Zhong, J. Phys. Chem. B, 2005, 109, 21593-21601.

36 V. Salgueirino-Maceira, M. A. Correa-Duarte, M. Farle, A. Lopez-Quintela, K. Sieradzki and R. Diaz, Chem. Mater., 2006, 18, 2701-2706.
37 Z. Xu, Y. Hou and S. Sun, J. Am. Chem. Soc., 2007, 129, 8698-8699.

38 H. Yu, M. Chen, P. M. Rice, S. X. Wang, R. L. White and S. H. Sun, Nano Lett., 2005, 5, 379-3982.

39 Y. Q. Li, Q. Zhang, A. V. Nurmikko and S. Sun, Nano Lett., 2005, 5, 1689-1692.

40 X. Jin, H. Li, S. Wang, N. Kong, H. Xu, Q. Fu, H. Gu and J. Ye, Nanoscale, 2014, 6, 14360-14370.

41 E. V. Shevchenko, M. I. Bodnarchuk, M. V. Kovalenko, D. V. Talapin, R. K. Smith, S. Aloni, W. Heiss and A. P. Alivisatos, Adv. Mater., 2008, 20, 4323-4329.

42 Y. Sun and Y. Xia, Analyst, 2003, 128, 686-691.

43 L. Lu, H. Wang and Y. Zhou, et al., Chem. Commun., 2002, 144-145.

44 K. I. Okazaki, T. Kiyama and K. Hirahara, et al., Chem. Commun., 2008, 691-693.

45 A. Pal and K. Esumi, J. Nanosci. Nanotechnol., 2007, 7, 2110-2115.

46 S. Pal and G. De, J. Nanosci. Nanotechnol., 2007, 7, 1994-1999.

47 C. Wang, H. Yin, R. Chan, S. Peng, S. Dai and S. Sun, Chem. Mater., 2009, 21(3), 433-435.

48 Q. Zhang, J. Xie, J. Liang and J. Y. Lee, Adv. Funct. Mater., 2009, 19, 1387.

49 T. T. Chng, L. Polavarapu, Q. H. Xu, W. Ji and H. C. Zeng, Langmuir, 2011, 27, 5633.

50 J. Crespo, A. Falqui, J. G. Barrasa, J. M. López-de-Luzuriag, M. Monge, M. E. Olmos, M. Rodríguez-Castillo, M. Sestu and K. Soulantica, J. Mater. Chem. C, 2014, 2, 2975-2984.

51 I. Lee, S. W. Hana and K. Kim, Chem. Commun., 2001, 1782-1783.

52 A. T. Izgaliev, A. V. Simakin and G. A. Shafeev, Quantum Electron., 2004, 34, 47.

53 P. S. Liu, W. P. Cai and H. B. Zeng, J. Phys. Chem. C, 2008, 112, 3261.

54 V. Amendola and M. Meneghetti, Phys. Chem. Chem. Phys., 2009, 11, 3805-3821.

55 H. Zeng, X. W. Du, S. C. Singh, S. A. Kulinich, S. Yang, J. He and W. Cai, Adv. Funct. Mater., 2012, 22, 1333-1353.

56 S. Barcikowski and G. Compagnini, Phys. Chem. Chem. Phys., 2013, 15, 3022-3026.

57 V. Amendola and M. Meneghetti, Phys. Chem. Chem. Phys., 2013, 15, 3027-3046.

58 S. Besner and M. Meunier, J. Phys. Chem. C, 2010, 114, 10403-10409.

59 I. Lee, S. W. Han and K. Kim, Chem. Commun., 2001, 1782-1783.

60 H. M. Bok, K. L. Shuford, S. Kim, S. KyuKim and S. Park, Langmuir, 2009, 25, 5266.

61 A. K. Gade, P. Bonde, A. P. Ingle, P. D. Marcato, N. Duran and M. K. Rai, J. Biobased Mater. Bioenergy, 2008, 2, 243-247.

62 P. Mukherjee, M. Roy, B. P. Mandal, G. K. Dey, P. K. Mukherjee and J. Ghatak, et al., Nanotechnology, 2008, 19, 103-110.

63 K. N. Thakkar, S. S. Mhatre and R. Y. Parikh, Nanomedicine, 2010, 6(2), 257-262. 
64 A. Ingle, A. Gade, S. Pierrat, C. Sonnichsen and M. K. Rai, Curr. Nanosci., 2008, 4, 141-144.

65 R. Bhattacharya and P. Mukherjee, Adv. Drug Delivery Rev., 2008, 11, 1289-1306.

66 H. R. Ghorbani, A. A. Safekordi, H. Attar and S. M. Rezayat Sorkhabadi, Chem. Biochem. Eng. Q., 2011, 25, 317-326.

67 M. M. Abou El-Nour, A. Eftaiha, A. Al-Warthan and R. A. Ammar, Arabian J. Chem., 2010, 3(3), 135-140.

68 M. Sastry, A. Ahmad, M. I. Khan and R. Kumar, Curr. Sci., 2003, 85, 162-170.

69 S. S. Shankar, A. Ahmad, R. Pasricha and M. Sastry, J. Mater. Chem., 2003, 13, 1822-1826.

70 J. R. Stephen and S. J. Maenaughton, Curr. Opin. Biotechnol., 1999, 10, 230-233.

71 R. K. Mehra and D. R. Winge, J. Cell. Biochem., 1991, 45(1), 30-40.

72 B. D. Reiss, C. Mao, D. J. Solis, K. S. Ryan, T. Thomson and A. M. Belcher, Nano Lett., 2004, 4, 1127-1132.

73 G. Southam and T. J. Beveridge, Geochim. Cosmochim. Acta, 1996, 60, 4369-4376.

74 D. Fortin and T. J. Beveridge, in Biomineralization. Biology to Biotechnology and Medical Applications, ed. E. Baeuerien, Wiley-VCH, Weinheim, 2000, p. 7.

75 K. Simkiss and K. M. Wilbur, Biomineralization, Academic, New York, NY, USA, 1989; S. Mann, Biomineralization: Principles and Concepts in Bioinorganic Materials Chemistry, Oxford University Press, Oxford, UK, 2001.

76 A. Ahmad, S. Senapati and M. I. Khan, et al., Nanotechnology, 2003, 7, 824-828.

77 X. Zhang, S. Yan, R. D. Tyagi and R. Y. Surampalli, Chemosphere, 2011, 4, 489-494.

78 K. Kalimuthu, R. S. Babu, D. Venkataraman, M. Bilal and S. Gurunathan, Colloids Surf., B, 2008, 65, 150-153.

79 P. Mukherjee, A. Ahmad, D. Mandal, S. Senapati, S. R. Sainkar, M. I. Khan, R. Ramani, R. Parischa, P. V. Ajaykumar, M. Alam, M. Sastry and R. Kumar, Angew. Chem., 2001, 113, 3697-3701.

80 P. Mukherjee, A. Ahmad, D. Mandal, S. Senapati, S. R. Sainkar, M. I. Khan, R. Ramani, R. Parischa, P. V. Ajayakumar, M. Alam, M. Sastry and R. Kumar, Angew. Chem., Int. Ed., 2001, 40, 3585-3588.

81 P. Mukherjee, S. Senapati, D. Mandal, A. Ahmad, M. I. Khan, R. Kumar and M. Sastry, ChemBioChem, 2002, 3, 461-463.

82 S. Senapati, A. Ahmad, M. I. Khan, M. Sastry and R. Kumar, Small, 2005, 5, 517-520.

83 B. D. Sawle, B. Salimath, R. Deshpande, M. D. Bedre, B. K. Prabhakar and A. Venkataraman, Sci. Technol. Adv. Mater., 2008, 3, 1-6.

84 D. Zheng, C. Hu, T. Gan, X. Dang and S. Hu, Sens. Actuators, B, 2010, 1, 247-252.

85 D. Caruntu, B. L. Cushing, G. Caruntu and C. J. O'Connor, Chem. Mater., 2005, 17, 3398-3402.

86 C. S. Levin, C. Hofmann, T. A. Ali, A. T. Kelly, E. Morosan, P. Nordlander, K. H. Whitmire and N. J. Halas, ACS Nano, 2009, 6, 1379-1388.
87 W. W. Yu, J. C. Falkner, C. T. Yavuz and V. L. Colvin, Chem. Commun., 2004, 2306-2307.

88 S. H. Sun, H. Zeng, D. B. Robinson, S. Raoux, P. M. Rice, S. X. Wang and G. X. Li, J. Am. Chem. Soc., 2004, 126, 273-279.

89 S. I. Stoeva, F. Huo, J.-S. Lee and C. A. Mirkin, J. Am. Chem. Soc., 2005, 127, 15362-15363.

90 C. Kallaway, L. M. Almond, H. Barr, J. Wood, J. Hutchings, C. Kendall and N. Stone, Photodiagn. Photodyn. Ther., 2013, 10, 207-219.

91 D. I. Ellis, D. P. Cowcher, L. Ashton, S. O'Hagan and R. Goodacre, Analyst, 2013, 138, 3871-3884.

92 Q. Tu and C. Chang, Nanomedicine, 2012, 8, 545-558.

93 M. D. Porter, R. J. Lipert, L. M. Siperko, G. Wang and R. Narayanana, Chem. Soc. Rev., 2008, 37, 1001-1011.

94 C. Mallon, E. Spain, T. E. Keyes and R. J. Forster, Chem. Commun., 2013, 49, 1380-1382.

95 J. Hu, P. C. Zheng, J. H. Jiang, G. L. Shen, R. Q. Yu and G. K. Liu, Analyst, 2010, 135(5), 1084-1089.

96 N. L. Rosi and C. A. Mirkin, Chem. Rev., 2005, 105, 1547-1562.

97 K. W. Kho, C. Y. Fu, U. S. Dinish and M. Olivo, J. Biophotonics, 2011, 4, 667-684.

98 S. McAughtrie, K. Faulds and D. Graham, J. Photochem. Photobiol., C, 2014, 21, 40-53.

99 T. Vo-Dinh, SERS Nanosensors and Nanoreporters: Golden Opportunities in Biomedical Applications SERS Nanosensors and Nanoreporters, Wiley Interdiscip. Rev.: Nanomed. Nanobiotechnol., 2015, 7(1), 17-33.

100 Y. Yang, J. Shi, G. Kawamura and M. Nogami, Scr. Mater., 2008, 58, 862-865.

101 Y. Cui, B. Ren, J. Yao, R. A. Gu and Z. Q. Tian, J. Phys. Chem. $B, 2006,110,4002-4006$.

102 R. Intartaglia, G. Das, K. Bagga, A. Gopalakrishnan, A. Genovese, M. Povia, E. Di Fabrizio, R. Cingolani, A. Diaspro and F. Brandi, Phys. Chem. Chem. Phys., 2013, 15, 3075.

103 M. Mandal, S. Kundu, S. K. Ghosh, N. R. Jana, M. Panigrahi and T. Pal, Curr. Sci., 2004, 86, 556-559.

104 Z. Q. Tian, B. Ren, J. F. Li and Z. L. Yang, Chem. Commun., 2007, 3514-3534.

105 J. J. Feng, U. Gernert, M. Sezer, U. Kuhlmann, D. H. Murgida, C. David, M. Richter, A. Knorr, P. Hildebrandt and I. M. Weidinger, Nano Lett., 2009, 9, 298-303.

106 P. Wu, Y. Gao, H. Zhang and C. Cai, Anal. Chem., 2012, 84, 7692-7699.

107 M. Fan, F. J. Lai, H. L. Chou, W. T. Lu, B. J. Hwang and A. G. Brolo, Chem. Sci., 2013, 4, 509-515.

108 J. S. Mohanty, P. L. Xavier, K. Chaudhari, M. S. Bootharaju, N. Goswami, S. K. Pal and T. Pradeep, Nanoscale, 2012, 4, 4255.

109 X. Yuan, Z. Luo, Y. Yu, Q. Yao and J. Xie, Chem. - Asian J., 2013, 8, 858.

110 H. Zhang, M. H. Harpster, W. C. Wilson and P. A. Johnson, Langmuir, 2012, 28, 4030-4037.

111 K. Kim, K. L. Kim and S. J. Lee, Chem. Phys. Lett., 2005, 403, 77-82.

112 H. T. Ngo, H. N. Wang, T. Burke, G. Ginsburg and T. Vo-Dinh, Anal. Bioanal. Chem., 2014, 406, 3335-3344. 
113 H. T. Ngo, H. N. Wang, A. M. Fales, B. P. Nicholson, C. W. Woods and T. Vo-Dinh, Analyst, 2014, 139, 5655.

114 A. Sivanesan, E. Witkowska, W. Adamkiewicz, Ł. Dziewit, A. Kaminska and J. Waluk, Analyst, 2014, 139, 1037.

115 R. Intartaglia, G. Das, K. Bagga, A. Gopalakrishnan, A. Genovese, M. Piova, E. Di Fabrizio, R. Cingolani, A. Diaspro and F. Brandi, Phys. Chem. Chem. Phys., 2013, 15, 3075.

116 Proc. SPIE 7909, Colloidal Quantum Dots/Nanocrystals for Biomedical Applications VI, 79090K.

117 P. Wu, Y. Gao, H. Zhang and C. Cai, Anal. Chem., 2012, 84, 7692-7699.

118 Y. Cao, R. Jin and C. A. Mirkin, J. Am. Chem. Soc., 2001, 123, 7961-7962.

119 Z. Wang, S. Zong, H. Chen, C. Wang, S. Xu and Y. Cui, Adv. Healthcare Mater., 2014, 3, 1889-1897.

120 J. H Park, R. Ramanathan, M. J. Sailor, T. A. Hatton and S. N. Bhatia, Adv. Mater., 2009, 21(31), 3175-3180.
121 S. C. Hayden, L. A. Austin, R. D. Near, R. Ozturk and M. A. El-Sayed, J. Photochem. Photobiol., A, 2013, 269, 34-41.

122 Y. W. Lee, N. H. Kim, K. Y. Lee, K. Kwon, M. Kim and S. W. Han, J. Phys. Chem. C, 2008, 112, 6717-6722.

123 Y. W. Lee, N. H. Kim, Y. Kim, S. W. Kang, J. H. Lee and S. W. Han, J. Phys. Chem. C, 2010, 114, 7689-7693.

124 G. W. Zhan, L. T. Ke, Q. B. Li, J. L. Huang, D. Hua, A. R. Ibrahim and D. H. Sun, Ind. Eng. Chem. Res., 2012, 51, 15753-15762.

125 S. Park, J. H. Lim, S. W. Chung and C. A. Mirkin, Science, 2004, 303, 348-351.

126 T. Ung, L. M. Liz-Marzan and P. Mulvaney, Langmuir, 1998, 14, 3740-3748.

127 J. Sinzig, U. Radtke, M. Quinten and U. Kreibig, Z. Phys. D: At., Mol. Clusters, 1993, 26, 242.

128 S. S. Shankar, A. Rai and A. Ahmad, et al., J. Colloid Interface Sci., 2004, 275(2), 496-502. 